\title{
Secondary Aortoduodenal Fistula Complicating Aortic Grafting, as a Cause of Intermittent Chronic Intestinal Bleeding
}

\author{
Michihiro Yabu, Seiichi Himeno, Yoshio Kanayama, Takayasu Furubayashi, Kazuo Kiriyama, \\ Yutaka Nagasawa, Rena Takakura, Tatsuo Katata, Norihito Iwao and Akio Orino*
}

\begin{abstract}
Intermittent intestinal bleeding persisted in a 77-year-old male, who had undergone grafting for abdominal aortic aneurysm. Each attack lasted for a few weeks and spontaneously resolved. Only a minute abnormality was found in the third portion of the duodenum; barium studies showed a segmental narrowing, but endoscopy disclosed only a small erosion in that portion. Massive and fatal gastrointestinal hemorrhage broke out 6 months after the onset of bleeding. Autopsy revealed an adhesion area with a small fistula formation between the duodenum and aorta. Even slight endoscopic findings should be considered suggestive of aortoenteric fistula in patients after aortic surgery.
\end{abstract}

(Internal Medicine 37: 47-50, 1998)

Key words: abdominal aortic aneurysm, small bowel endoscopy

\section{Introduction}

Fistula formation between the aorta and the alimentary tract is one of the causes of gastrointestinal bleeding, and without successful surgical treatment the prognosis is very poor $(1,2)$. It is classified into primary and secondary types. The primary type is very rare and usually occurs following spontaneous rupture of an abdominal aortic aneurysm into the intestinal tract. The secondary type generally occurs as a complication of abdominal aortic aneurysm repairs, and has accounted for the greater part of aortoenteric fistula with the current increase in aortic surgery. Secondary aortoenteric fistula develops at any time after aortic reconstructive surgery and the incidence has been reported to be from less than $1 \%$ to $4 \%$. Due to the anatomical proximity, the majority involve the duodenum with the proximal suture line of an aortic prosthesis. Although most patients have premonitory bleeding episodes before catastrophic massive hemorrhage, diagnosis has rarely been made before laparotomy or autopsy. We report a case of secondary aortoduodenal fistula, in whom every diagnostic approach hardly detected the bleeding site in his lifetime. Retrospectively, endoscopic findings, though only slightly abnormal, could provide a diagnostic clue in this case.

\section{Case Report}

A 77-year-old male was admitted in June 1995, because of exertional dyspnea due to lung emphysema. His past history included aortofemoral graft insertion for abdominal aortic aneurysm 10 years before, myocardial infarction 9 years before, and graft insertion for thoracic aortic aneurysm one year before.

On physical examination, he was $163 \mathrm{~cm}$ tall and weighed 64 $\mathrm{kg}$. His temperature was $36.3^{\circ} \mathrm{C}$, pulse 80 , and blood pressure $142 / 82 \mathrm{mmHg}$. A postoperative scar was noted on the anterior midline from the upper chest to lower abdomen. Superficial lymph nodes were not palpable. The respiratory and heart sounds were normal. The liver and spleen were not felt, and there was no palpable abdominal mass, tenderness, or bruit.

Laboratory tests (Table 1) were within normal limits except for moderate elevations of fibrin degradation products-D dimer, $\gamma$-glutamyl transpeptidase, and total cholesterol.

The patient was treated with theophylline, and after a 4month hospital stay, the respiratory symptoms subsided. In October 1995, when discharge was due, he suddenly developed an attack of melena with dark reddish and paste-like appearance once to three times a day. The hemorrhage stopped spontaneously after lasting for about a weci- "imilar melena attacks recurred intermittently afterwards (Fig. 1). During the episodes of intestinal bleeding, the patient did not complain of abdominal

From the Department of Internal Medicine, Ashiya Municipal Hospital and *the Department of Gastroenterology, Kobe City General Hospital, Hyogo Received for publication May 6, 1997; Accepted for publication October 8, 1997

Reprint requests should be addressed to Dr. Seiichi Himeno, the Department of Internal Medicine, Ashiya Municipal Hospital, 39-1, Asahigaoka, Ashiya, Hyogo 659 
Table 1. Laboratory Data on Admission

\begin{tabular}{lrlr}
\hline Urinalysis & & Blood chemistry & \\
Protein & $(-)$ & Total protein & $6.9 \mathrm{~g} / \mathrm{dl}$ \\
Sugar & $(-)$ & Albumin & $4.6 \mathrm{~g} / \mathrm{dl}$ \\
Blood & $(-)$ & Aspartate aminotransferase & $18 \mathrm{IU} / l$ \\
Stool & & Alanine aminotransferase & $13 \mathrm{IU} / l$ \\
Blood & $(-)$ & Lactate dehydrogenase & $408 \mathrm{IU} / l$ \\
Parasite ova & $(-)$ & Alkaline phosphatase & $229 \mathrm{IU} / l$ \\
Peripheral blood & & $\gamma$-glutamyl transpeptidase & $52 \mathrm{IU} / l$ \\
Red blood cell count & $452 \times 10^{4} / \mu \mathrm{l}$ & Total bilirubin & $0.7 \mathrm{mg} / \mathrm{dl}$ \\
Hemoglobin & $14.6 \mathrm{~g} / \mathrm{dl}$ & Total cholesterol & $223 \mathrm{mg} / \mathrm{dl}$ \\
Hematocrit & $42.5 \%$ & Triglyceride & $95 \mathrm{mg} / \mathrm{dl}$ \\
White blood cell count & $5,900 / \mu 1$ & Amylase & $89 \mathrm{IU} / l$ \\
Platelet count & $15.4 \times 104 / \mu l$ & Creatine kinase & $77 \mathrm{IU} / l$ \\
Serological test & & Blood urea nitrogen & $12.0 \mathrm{mg} / \mathrm{dl}$ \\
C-reactive protein & $1.0 \mathrm{mg} / \mathrm{dl}$ & Creatinine & $0.9 \mathrm{mg} / \mathrm{dl}$ \\
Treponema pallidum hemagglutination & $(-)$ & Uric acid & $6.7 \mathrm{mg} / \mathrm{dl}$ \\
Erythrocyte sedimentation rate & $7 \mathrm{~mm} / \mathrm{h}$ & Na & $143 \mathrm{mEq} / l$ \\
Coagulation and Fibrinolysis & & K & $4.4 \mathrm{mEq} / l$ \\
Prothrombin time & $11.8 \mathrm{sec}$ & Cl & $103 \mathrm{mEq} / l$ \\
Activated partial thromboplastin time & $28.6 \mathrm{sec}$ & Glucose & $75 \mathrm{mg} / \mathrm{dl}$ \\
Fibrinogen & $398 \mathrm{mg} / \mathrm{dl}$ & Tumor marker & \\
Fibrin degradation products-D dimer & $2.0 \mu \mathrm{g} / \mathrm{ml}$ & Carcinoembryonic antigen & $1.0 \mathrm{ng} / \mathrm{ml}$ \\
Plasminogen & $106 \%$ & $\alpha$-fetoprotein & $2.1 \mathrm{ng} / \mathrm{ml}$ \\
Antithrombin-III & $92 \%$ & Carbohydrate antigen $19-9$ & $13.1 \mathrm{U} / \mathrm{ml}$ \\
\hline
\end{tabular}

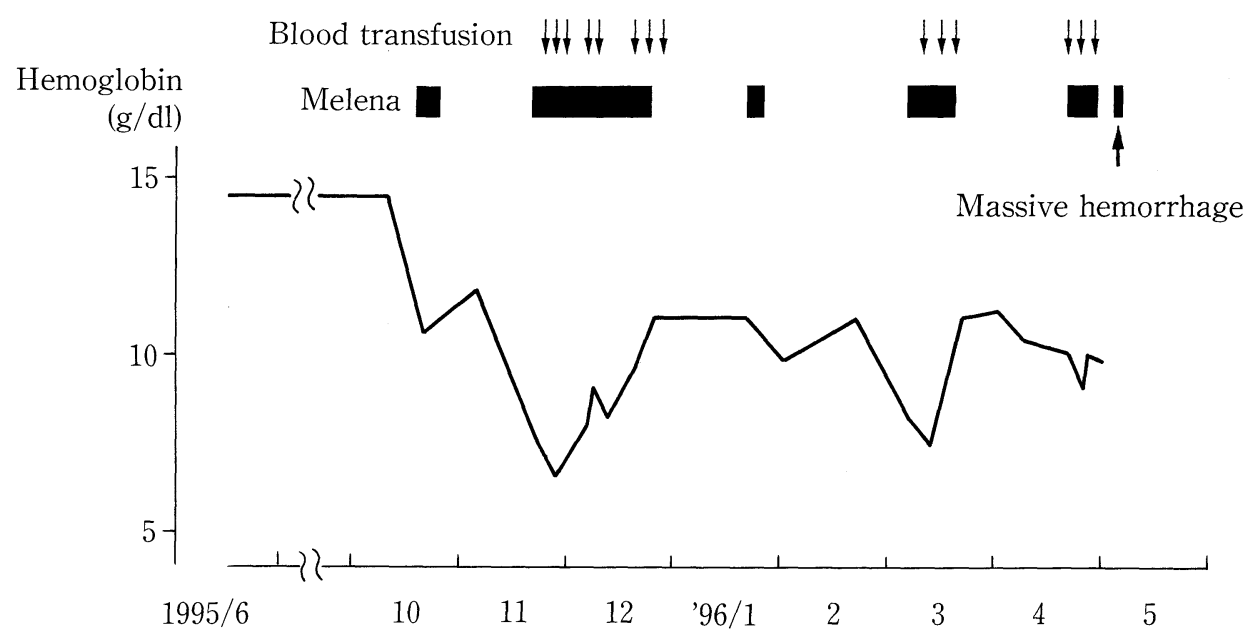

Figure 1. Clinical course.

pain, and, though with support of frequent blood transfusions, he was not complicated with hypovolemic shock until the last and fatal hemorrhage.

Repeated fiberoptic endoscopic examinations failed to detect the origin of the melena attacks in the esophagus and stomach as well as in the distal ileum, colon and rectum. Barium studies of the small intestine were normal except for a segmental narrowing in the third portion of the duodenum (Fig. 2A). Fiberscopy of the duodenum and jejunum, using a fiberscope of
Olympus SIF Type 10 on January 25 in 1996, disclosed only a small erosion without any abnormalities in the surrounding mucosa (Fig. 2B). Precontrast abdominal computed tomography showed a stone in the gall bladder, but there was no abnormal mass, lymph node swelling, pseudoaneurysm formation of the aorta, or perigraft ectopic gas collection. Examinations with a contrast medium were not performed due to the patient's allergy to iodine.

The origin of the bleeding thus remained unclear. 

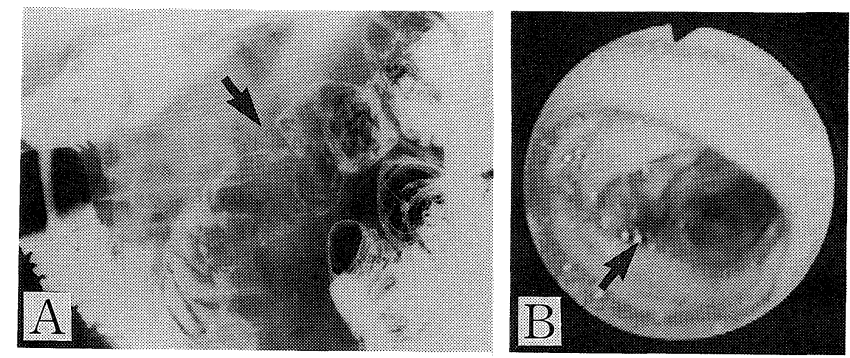

Figure 2. A) A barium study shows a segmental narrowing (arrow) in the third portion of the duodenum. B) Endoscopy shows a small erosion (arrow) in the segment.

Aortoduodenal fistula was considered a probable diagnosis based on his past history of abdominal aortic reconstruction together with the radiological and endoscopic findings of the duodenum, but surgical treatment was deterred because of his poor cardiac function. In May 1996, the patient suddenly vomited large quantities of bright-red blood and had a bout of severe melena. He fell into hyovolemic shock and died soon afterward.

At autopsy, the entire gastrointestinal tract was filled with blood, and the aorta showed severe atherosclerosis. An adhesion area was found between the third portion of the duodenum and the abdominal aorta at the proximal aortic suture line of the graft. A round depression filled with blood coagula, about $5 \mathrm{~mm}$ in diameter, was present on the aortic inner surface of the adhesion area (Fig. 3A), while the mucosal surface of the duodenum had a circular erosion, $2 \mathrm{~mm}$ in diameter (Fig. 3B). A small fistulous communication was confirmed between the two lesions. Because there were no other abnormalities in the gastrointestinal tract, the origin of the bleeding was ascribed to secondary aortoduodenal fistula. Histological study of the adhesion area disclosed severe atherosclerotic change with superficial thrombus formation in the aorta (Fig. 4A), and in the duodenum a thickening of the submucosa and destruction of the muscular layer (Fig. 4B).

\section{Discussion}

Aortoenteric fistula is one of the serious complications of aortic reconstructive surgery. The exact pathogenesis is unknown but two mechanisms are proposed. One is a vibratory pressure of the aortic graft to the bowel wall, and the other is a bacterial infection of the prosthesis $(1,2)$. The present case did not show the signs of infection such as fever and leukocytosis through the entire clinical course, and postmortem examination revealed no evidence of active infection around the graft. Although the possibility of low grade prosthetic infection is not entirely excluded, the autopsy findings rather indicate that mechanical factors following postoperative adhesion between the duodenum and aorta may contribute to fistula formation.

The etiologic relationship of the preceding lung emphysema to the outbreak of aortoduodenal fistula is unclear in this case,
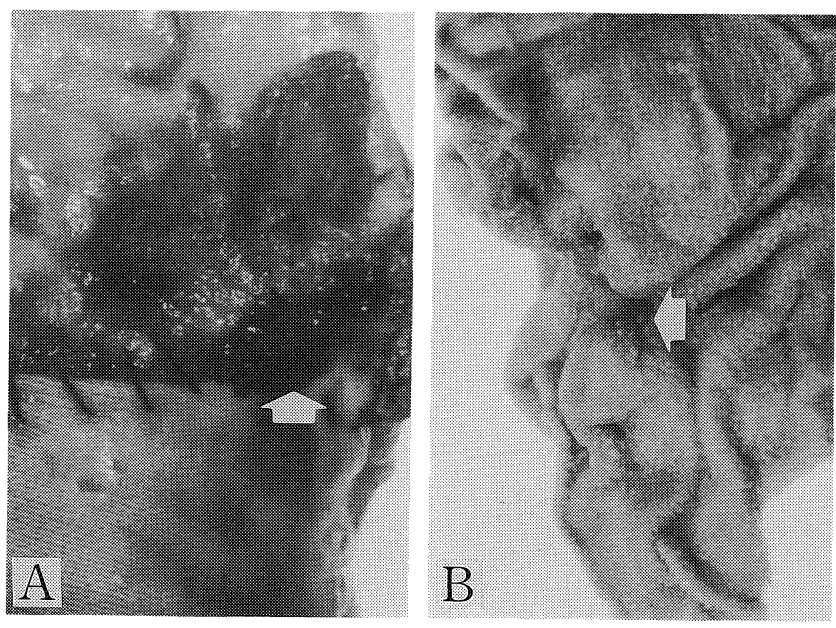

Figure 3. Photographs of the aortic and duodenal sides of the adhesion area. A) A round depression filled with blood coagula (arrow) is seen in the aorta $(\times 2)$. B) A circular erosion (arrow) is seen in the third portion of the duodenum $(\times 2)$.
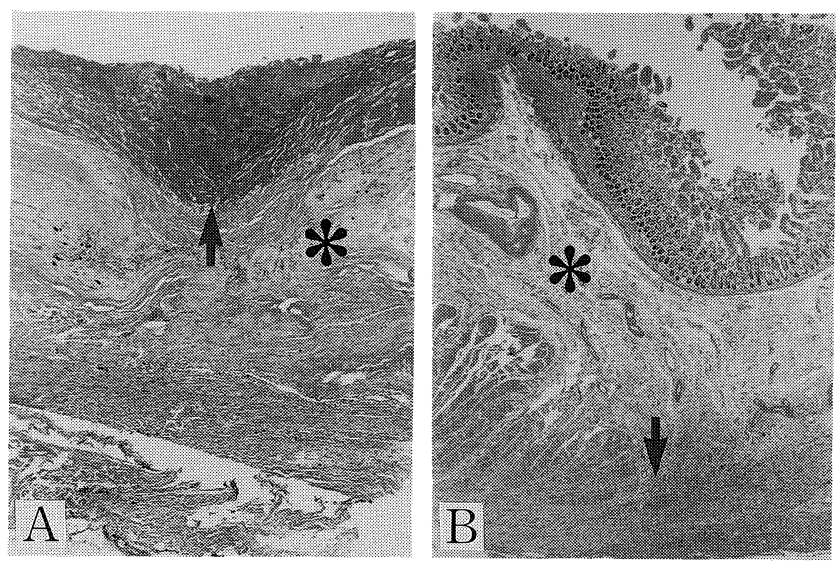

Figure 4. Photomicrographs of the adhesion area between the aorta and duodenum. A) Severe atherosclerotic change (asterisk) with superficial thrombus formation (arrow) is seen in the aorta (HE stain, $\times 20)$. B) A thickening of the submucosa (asterisk) and destruction of the muscular layer (arrow) are seen in the duodenum (HE stain, $\times 10$ ).

but the clinical course findings that intestinal bleeding occurred after respiratory symptoms had subsided suggests that both are not very closely related.

Clinically, aortoenteric fistula usually manifests with catastrophic gastrointestinal hemorrhage, leading to a sudden death unless surgical treatment is successfully made. Not so severe and repeated bleeding episodes often precede massive hemorrhage presumably because of a transient sealing of fistula by thrombosis $(1,2)$. But the duration is usually from days to weeks, and it rarely extends as long as 6 months, as in the present case. The small size of the fistula and the histological 


\section{YABU et al}

repair by chronic inflammation appeared to explain the milder and prolonged clinical course as well as the diagnostic difficulty.

Gastrointestinal bleeding occasionally meets difficulty in diagnosis $(3,4)$. Causes of obscure bleeding include neoplasms of the small bowel, vascular anomalies, and aortoenteric fistula. As for the diagnosis of aortoenteric fistula, aortographic visualization of fistula formation is not helpful unless the fistula is large enough and bleeding is active. Computed tomography can demonstrate findings suggestive of the disease, such as pseudoaneurysm formation and perigraft ectopic gas collection $(5,6)$. Our case showed none of those signs. Small bowel enteroscopy is reported to be an effective tool in the evaluation of patients with chronic gastrointestinal bleeding of obscure origin (7), and is helpful for the diagnosis of aortoenteric fistula (8-10). Findings suggestive of the diagnosis include a pulsating extraluminal mass, ulceration, and active bleeding. Recognition of the graft through the intestinal wall is diagnostic. Unlike these typical findings, our case presented only a small erosion. Even with such a slight finding, aortoenteric fistula should be considered in any patient with gastrointestinal bleeding who has previously undergone aortic reconstructive surgery.

\section{References}

1) Nagy SW, Marshall JB. Aortoenteric fistulas. Recognizing a potentially catastrophic cause of gastrointestinal bleeding. Postgrad Med 93: 211, 1993.

2) Dachs RJ, Berman J. Aortoduodenal fistula. Am Fam Physician 45: 2610, 1992.

3) Thompson JN, Salem RR, Hemingway AP, et al. Specialist investigation of obscure gastrointestinal bleeding. Gut 28: 47, 1987.

4) Lau WY, Fan ST, Wong SH, et al. Preoperative and intraoperative localisation of gastrointestinal bleeding of obscure origin. Gut 28: 869, 1987.

5) Kew J, Davey I, Metreweli C. Case of the season. Infected false aneurysm of the aorta with aorto-enteric fistula. Semin Roentgenol 31: 182, 1996.

6) Low RN, Wall SD, Jeffrey RB Jr, Sollitto RA, Reilly LM, Tierney LM Jr. Aortoenteric fistula and perigraft infection: evaluation with CT. Radiology 175: 157, 1990

7) Lewis BS, Waye JD. Chronic gastrointestinal bleeding of obscure origin: role of small bowel enteroscopy. Gastroenterology 94: 1117, 1988.

8) Abernethy W, Sekijima JH. Images in clinical medicine. Aortoenteric fistula. N Engl J Med 336: 27, 1997.

9) Puppala AR, Munaswamy M, Doshi AM, Steinheber FU. Endoscopic diagnosis of aortoduodenal fistula. Complication of abdominal aortic bypass grafts. Am J Gastroenterol 73: 414, 1980.

10) Brand EJ, Sivak MV Jr, Sullivan BH Jr. Aortoduodenal fistula. Endoscopic diagnosis. Dig Dis Sci 24: 940, 1979. 